\title{
Surface Modifications Induced by High Fluxes of Low Energy Helium lons
}

SUBJECT AREAS:

MATERIALS SCIENCE

PLASMA PHYSICS

Received

17 December 2014

Accepted

19 March 2015

Published

28 April 2015

Correspondence and requests for materials should be addressed to i.T. (i.tanyeli@differ.nl)

\author{
İrem Tanyeli ${ }^{1}$, Laurent Marot ${ }^{2}$, Daniel Mathys ${ }^{3}$, Mauritius C. M. van de Sanden ${ }^{1}$ \& \\ Gregory De Temmerman ${ }^{1,4}$
}

\begin{abstract}
${ }^{1}$ FOM-Institute DIFFER, Dutch Institute For Fundamental Energy Research, Edisonbaan 14, 3439MN, Nieuwegein, The Netherlands, ${ }^{2}$ Department of Physics, University of Basel, Klingelbergstrasse 82, CH-4056 Basel, Switzerland, ${ }^{3}$ Centre of Microscopy, University of Basel, Klingelbergstrasse 50/70, CH-4056 Basel, Switzerland, ${ }^{4}$ ITER Organization, Route de Vinon sur Verdon, CS 90 046- 13067 St Paul Lez Durance Cedex, France.
\end{abstract}

Several metal surfaces, such as titanium, aluminum and copper, were exposed to high fluxes (in the range of $\left.10^{23} \mathrm{~m}^{-2} \mathrm{~s}^{-1}\right)$ of low energy $(<100 \mathrm{eV})$ Helium $(\mathrm{He})$ ions. The surfaces were analyzed by scanning electron microscopy and to get a better understanding on morphology changes both top view and cross sectional images were taken. Different surface modifications, such as voids and nano pillars, are observed on these metals. The differences and similarities in the development of surface morphologies are discussed in terms of the material properties and compared with the results of similar experimental studies. The results show that $\mathrm{He}$ ions induced void growth and physical sputtering play a significant role in surface modification using high fluxes of low energy He ions.

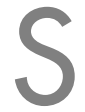
urface structuring by energetic ion bombardment has been widely studied and considered as an efficient surface processing technique, since it is fast, cost effective and various types of material can be processed by this technique. This so-called ion beam sputtering technique is attributed to the removal of atoms from the surface due to the impact of energetic ions. ${ }^{1}$ Both experimental and theoretical studies have been conducted for a wide range of conditions, such as ion species, ion energy, surface temperature and angle of ion bombardment. ${ }^{1-3}$ As a particular case, the interaction of helium ions with metal surfaces, especially with tungsten, has long been studied extensively because of helium production in fusion reactors. ${ }^{4-7}$ More recently, significant surface modifications were observed on tungsten under low-energy $\mathrm{He}$ ion irradiation, with ion energies below the threshold for damage creation, and investigated as a function of surface temperature, ion flux and exposure time..$^{8-11}$ These studies revealed the formation of a fine nanostructure exhibiting a high porosity of up to $90 \%$ and high light absorption. ${ }^{12-14}$ The size of those nanostructures and thickness of the nanostructured layer could be controlled by surface temperature and plasma exposure time, respectively. ${ }^{15}$ After these results on tungsten, investigations were extended to other metals. Similar nanostructure formation has been observed for molybdenum, nickel and iron surfaces under low energy He ion irradiation. ${ }^{15-17}$ Although a clear explanation of why some metals can be modified more easily than others is still missing, one could categorize these metals with respect to their crystal structure; except nickel, all of these metals have body centered cubic (bcc) type crystal structure.

Due to their controllable growth and porous structure, helium induced nanostructured surfaces appear to have a great potential to be used for various applications requiring high surface area and high light absorption, such as photo electrochemical water splitting for example. ${ }^{18-20}$ Indeed, an enhancement in the photocatalytic activity has been reported for nanostructured $\mathrm{WO}_{3}$, prepared by low-energy helium ion exposure and followed by annealing. ${ }^{21}$

In this study, we explore the effect of low-energy helium ion exposure of several metal surfaces, such as titanium (Ti), aluminum $(\mathrm{Al})$ and copper $(\mathrm{Cu})$. The choice of those metals was driven by the aforementioned application of photocatalytic properties of these metals in oxidized form. The influence of the different crystal structures on helium-plasma irradiation induced surface modification is studied and results are compared with both theoretical and experimental studies in literature.

Effect of low energy He ions on surface modification of metals. Helium is a chemically inert gas and has almost zero solubility in metals, but can diffuse rapidly through the metal surface because of its relatively small size. These features of helium lead to bubble formation underneath the surface at crystallographic defects. Experimental and theoretical studies have shown that helium irradiation induced damages could be obtained even in the absence of displacement damage and native defects. ${ }^{9,13,22}$ 
Theoretical works conducted on tungsten and iron agree on a qualitative description of the formation and growth of clusters (or bubbles). ${ }^{23,24}$ Interstitial helium atoms are very mobile and tend to coalesce to form interstitial clusters. Both the interstitial $\mathrm{He}$ atoms and clusters can act as traps for incoming He atoms, which indicates a self-trapping ability of He. Once an interstitial He cluster reaches a sufficient size, it punches out a metal self-interstitial and forms a relatively immobile helium-vacancy cluster. Helium diffusion is required for nucleation of bubbles and their growth. ${ }^{24}$ In the case of negligible ion radiation damages, helium diffusion is dominated by interstitial migration and for higher temperatures $\left(>0.5 T_{m}\right.$, where $T_{m}$ is the melting temperature) the interstitially diffusing $\mathrm{He}$ atoms are mainly trapped by thermal vacancies, since the concentration of thermal vacancies tends to increase with temperature. ${ }^{24}$ There are 12 tetrahedral and 6 octahedral, 8 tetrahedral and 4 octahedral, 4 tetrahedral and 2 octahedral interstitial sites existing in metals with bcc, face centered cubic (fcc) and hexagonal close packed (hcp) type crystal structure, respectively. ${ }^{25}$ Since the interstitial sites could assist the He diffusion in the metal lattice, one could expect that helium trapping would be easiest in bcc type metals and less likely in closely packed metals. In addition to these self-interstitials in the metal, $\mathrm{He}$ ions could induce extra interstitials as mentioned above, which assist He diffusion and consequently nucleation, in the metal even if their energies are well below the knock-on energy for displacement damage. Besides, detrapping has to be taken into account during the discussion of helium trapping in the metals. The substitutional detrapping energies for bcc type metals listed in table 1 indicate that release of He atoms in a metal lattice is hardly expected from these metals. The formation and migration energies of He interstitials for different metals are compared in table $1 .{ }^{26-32}$ Although the values do not seem to differ much from each other, slightly higher formation and migration energies of hcp metal from the ones for fcc metals could indicate that He diffusion and clustering processes could be slower for hcp metals. Hence, one might expect that hcp-type metals will be less prone to He ion-induced morphology changes.

The experimental results have showed that nanobubble formation near the surface is necessary but not sufficient to give rise to nanostructure formation..$^{33}$ The nanostructuring on tungsten surface is achieved for a surface temperature range of $\sim 0.25<T / T_{m}<0.55$. $^{8}$ The upper boundary of the temperature range for nanostructure formation is defined by rapid surface diffusion, which could lead to surface smoothing and eventually disappearance of the nanostructure. ${ }^{8,34}$ The slow bubble growth rate is considered as the limiting factor at low temperature. Similar nanostructuring has been observed in the experimental studies conducted on Mo and Fe for intermediate temperatures $\left(0.3-0.5 T_{m}\right){ }^{15,17}$ The relation between swelling rate of helium bubbles and $T / T_{m}$ has already been reported. ${ }^{34}$ Relying on both experimental and theoretical studies, the temperature ranges worth to study for surface modification of different metals could be determined in advance.

\section{Methods}

Polycrystalline titanium (99.99\% purity, Goodfellow), copper ( $\geq 99.95 \%$ purity, Salomon's Metalen) and aluminum (95.90\% purity, Salomon's Metalen) samples were exposed to pure helium plasma in Pilot-PSI, a high-flux linear plasma

Table 1 | Formation, migration energies of He interstitial and substitutional detrapping energies for W, Mo, Fe, Ti, Al and Cu.

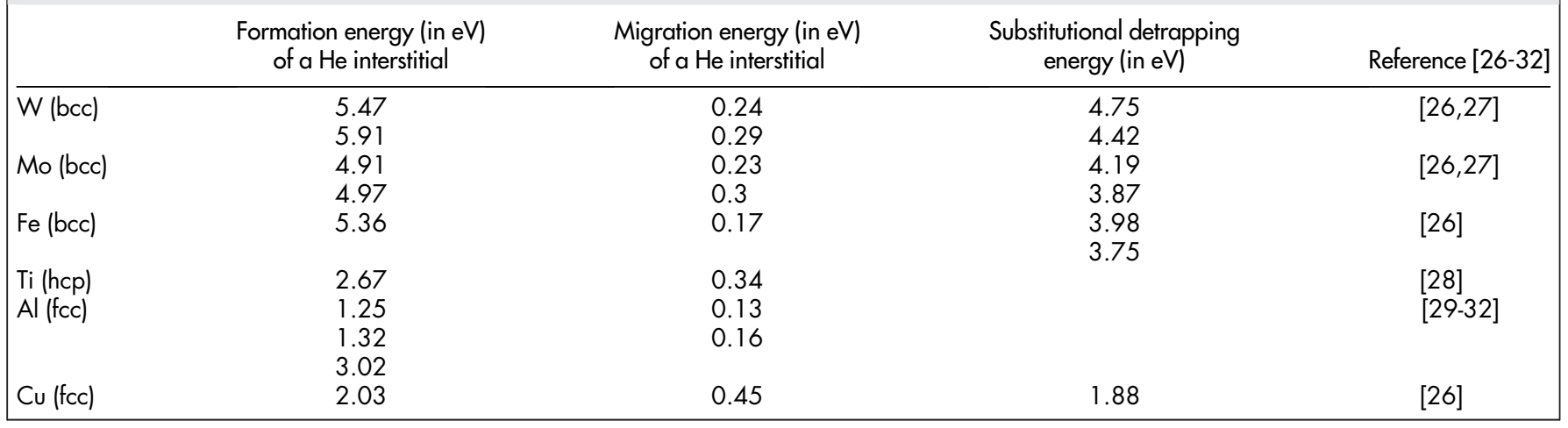

Table 2 | Experimental conditions.

\begin{tabular}{|c|c|c|c|c|c|}
\hline & Metal & lon energy $(\mathrm{eV})$ & Surface temperature $\left({ }^{\circ} \mathrm{C}\right)$ & $\mathrm{T} / \mathrm{T}_{\mathrm{m}}$ & Time (min) \\
\hline ii & & 45 & 600 & 0.45 & 10 \\
\hline iv & & 45 & 850 & 0.58 & 10 \\
\hline $\mathrm{v}$ & & 45 & 1000 & 0.66 & 10 \\
\hline vi & & 70 & 850 & 0.58 & 10 \\
\hline vii & & 70 & 1000 & 0.66 & 10 \\
\hline$x$ & & 35 & 250 & 0.56 & 10 \\
\hline$x i$ & $\mathrm{Cu}(\mathrm{fcc})$ & 25 & 150 & 0.31 & 10 \\
\hline xii & & 25 & 250 & 0.39 & 10 \\
\hline xiii & & 25 & 350 & 0.46 & 10 \\
\hline xiv & & 25 & 400 & 0.50 & 10 \\
\hline$x V$ & & 25 & 500 & 0.57 & 10 \\
\hline
\end{tabular}




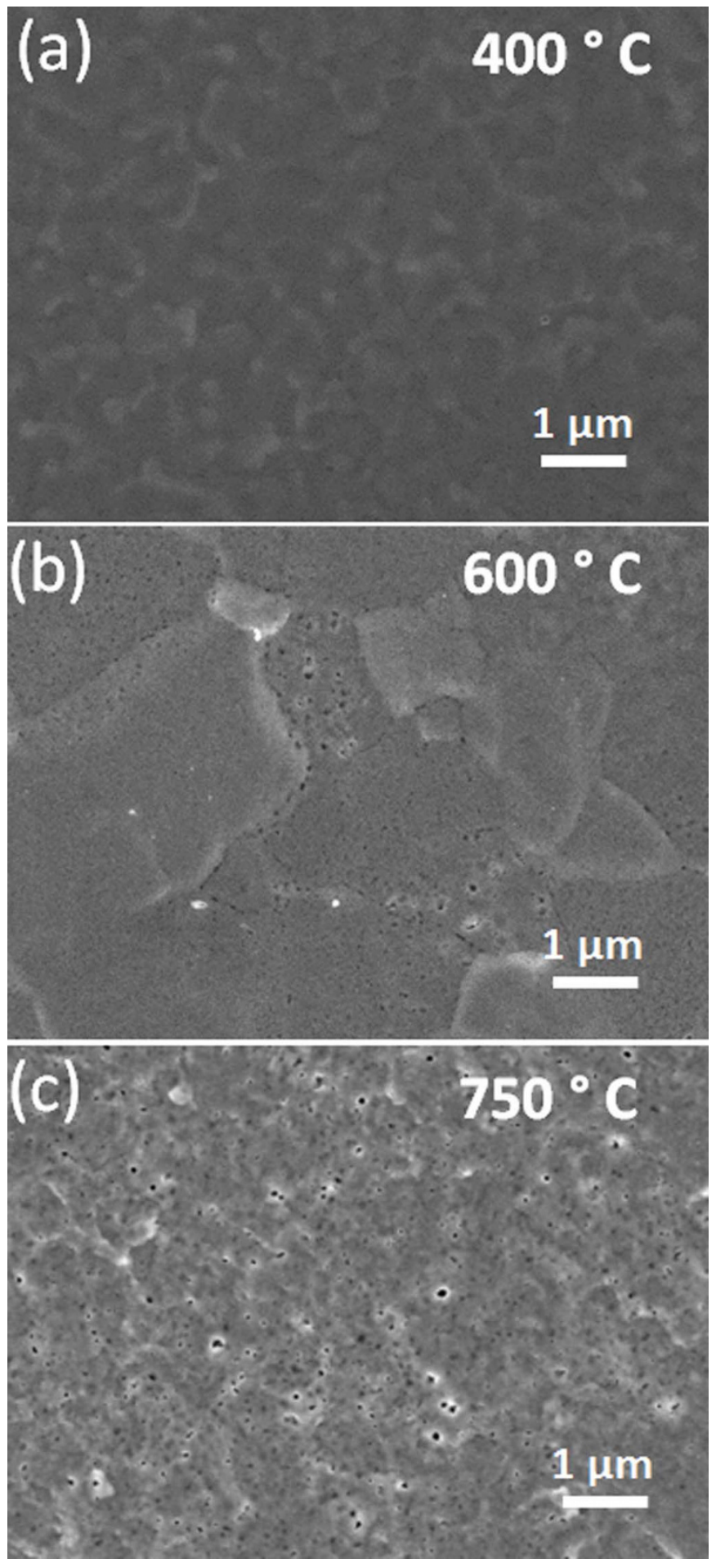

Figure 1 | SEM images of Ti samples which are exposed to helium plasma with the surface temperature of $400^{\circ} \mathrm{C}\left(0.35 \mathrm{~T}_{\mathrm{m}}\right), 600^{\circ} \mathrm{C}\left(0.45 \mathrm{~T}_{\mathrm{m}}\right)$ and $750^{\circ} \mathrm{C}\left(0.53 \mathrm{~T}_{\mathrm{m}}\right)$ for 10 minutes: (i)-(iii) (a-c), respectively.

generator. ${ }^{35}$ The plasma is generated by a thermal plasma (cascaded arc) source and confined by an axial magnetic field. More detailed information about the experimental setup can be found elsewhere. ${ }^{35}$ The magnetic field was set to $0.2 \mathrm{~T}$ during our experiments. The plasma density profile has a Gaussian shape and the maximum ion flux to the surface was in the range of $2-7 \times 10^{23} \mathrm{~m}^{-2} \mathrm{~s}^{-1}$. The samples were clamped on a water cooled target holder by a ring made from molybdenum. In order to have a better thermal contact, a Grafoil ${ }^{\circledR}$ layer was inserted between the sample and the target holder. The samples are negatively biased to control the ion energy, which is calculated with respect to plasma potential and sheath entrance voltage. Further details about ion energy calculation can be found in Ref 36 .

Polycrystalline samples, which are $20 \mathrm{~mm}$ in diameter and $1 \mathrm{~mm}$ in thickness, were mechanically polished with $\mathrm{SiC}$ grinding papers and followed by 3 and $1 \mu \mathrm{m}$ diamond
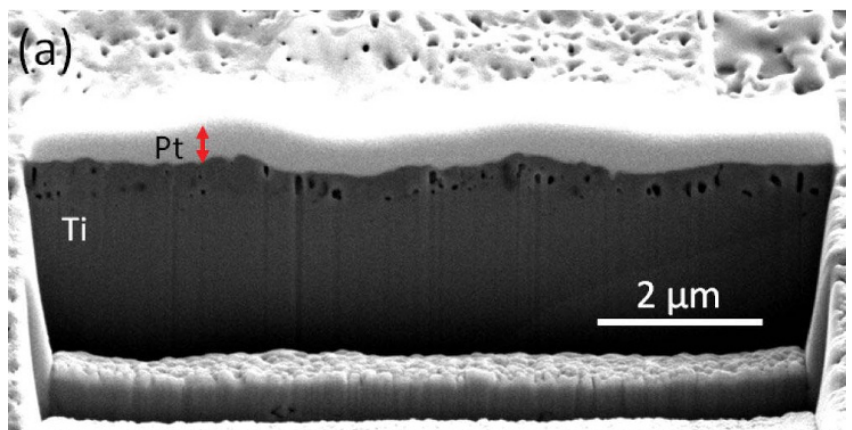

(b)

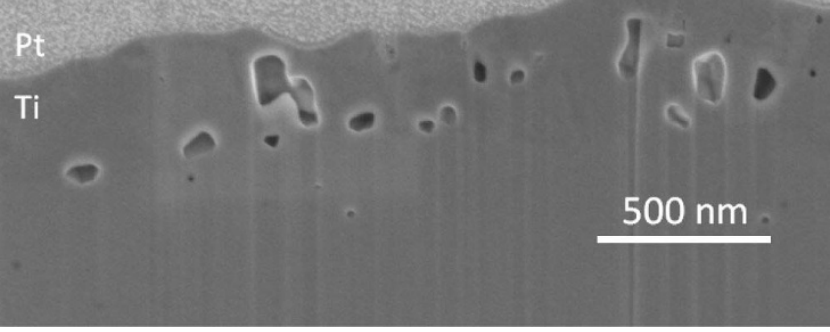

Figure $2 \mid$ Cross section images of Ti sample (exposed for 10 minutes with surface temperature of $750^{\circ} \mathrm{C}$ ) (iii) taken under low (a) and high magnification (b).

and $0.05 \mu \mathrm{m}$ alumina suspensions. The metals that we worked with have different levels of hardness, so that different polishing recipes have been followed. For Ti and $\mathrm{Cu}$ samples we used 320 to 2400 grit $\mathrm{SiC}$ papers and for $\mathrm{Al}$ samples 500 to 2400 grit $\mathrm{SiC}$ papers. The mirror finish polished samples were cleaned with a basic procedure, acetone, ethanol, de-ionized water in ultrasonic bath and for easy rinsing a further bath with ethanol repeated at the end.

During plasma exposure, the peak temperature was measured by a multiwavelength pyrometer (FMPI SpectroPyrometer, FAR Associates), which measures in the wavelength range of 900-1600 $\mathrm{nm}$. In addition, an infrared camera (FLIR A645 SC) was used to measure the $2 \mathrm{D}$ surface temperature profile and was also used in case of temperatures lower than the detection limit of the pyrometer.

The surfaces were analyzed by high resolution scanning electron microscopy (SEM, Hitachi S-4800 field emission at $5 \mathrm{kV}$ ) and atomic force microscopy (Bruker Dimension Edge AFM ) in order to investigate the modifications after plasma exposures. For cross sectional imaging, the samples were prepared by focused ion beam (Dual Beam FIB/SEM) milling method.

\section{Results}

Titanium. All experimental conditions are listed in table 2.Titanium surfaces were irradiated by low energy $(\sim 45 \mathrm{eV}) \mathrm{He}$ ions with flux of

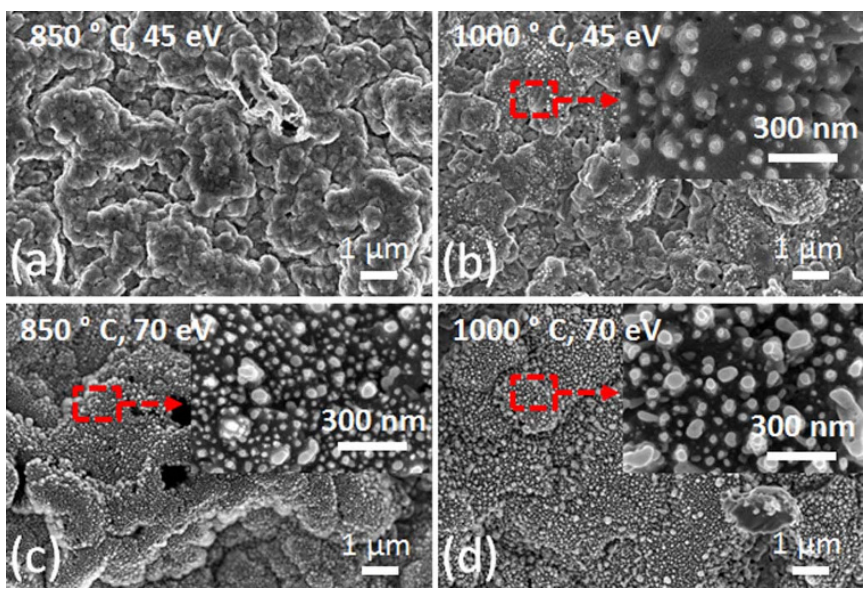

Figure 3 SEM images of samples which are irradiated by He ions with ion energies of $45 \mathrm{eV}$ at surface temperatures of $850^{\circ} \mathrm{C}\left(0.58 \mathrm{~T}_{\mathrm{m}}\right)$ and $1000^{\circ} \mathrm{C}$ $\left(0.66 \mathrm{~T}_{\mathrm{m}}\right)$ (sample(iv) (a), sample (v) (b)) and ion energies of $70 \mathrm{eV}$ at surface temperatures of $850^{\circ} \mathrm{C}$ and $1000^{\circ} \mathrm{C}$ (sample (vi) (c) and sample (vii) (d)). 


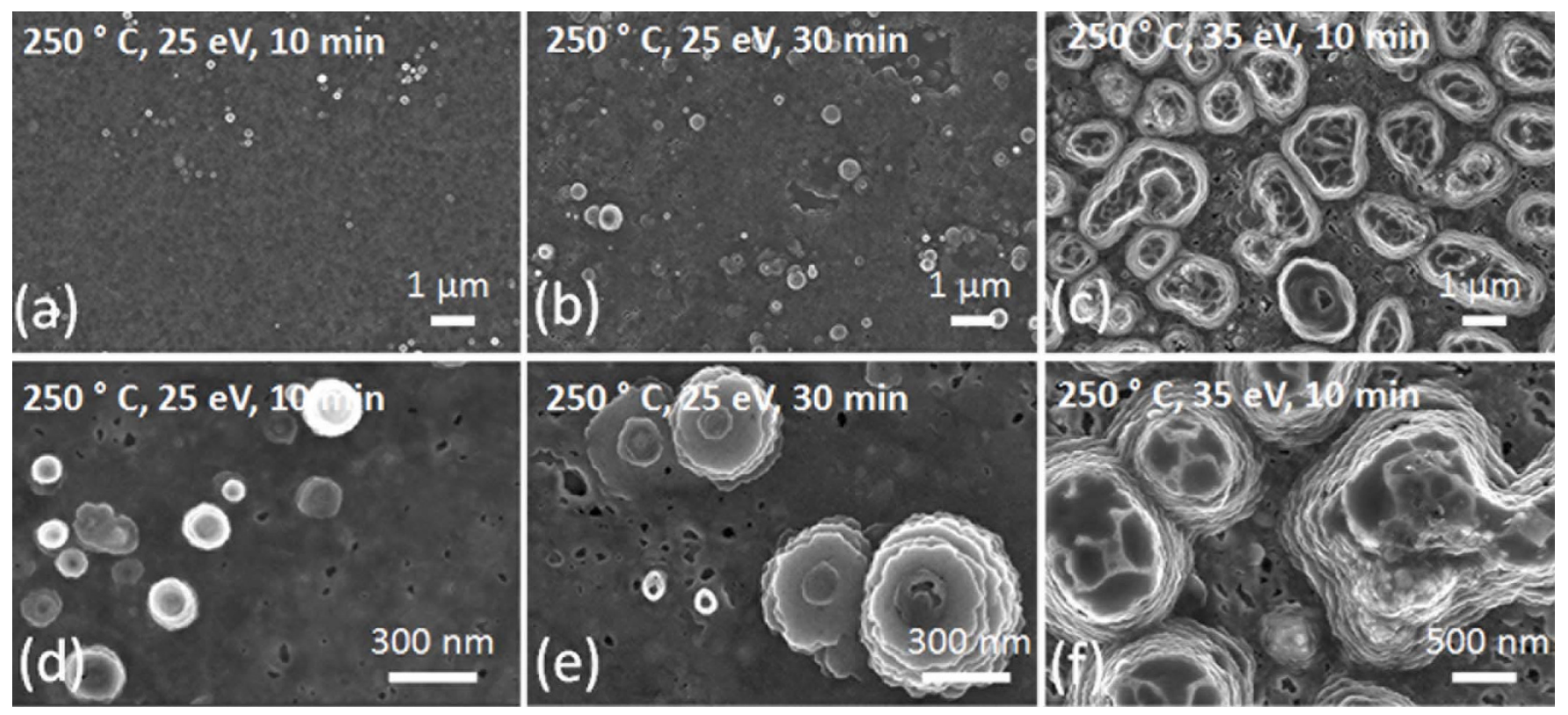

Figure 4 SEM images of Al samples, which are irradiated by He ions with an energy of $25 \mathrm{eV}$ at a surface temperature of $250^{\circ} \mathrm{C}\left(0.56 \mathrm{~T}_{\mathrm{m}}\right)$ for 10 minutes and 30 minutes (samples (viii) and (ix)) and with ion energy of $35 \mathrm{eV}$ for 10 minutes (sample (x)), taken under low (a), (b), (c) and high (d), (e), (f) magnification, respectively.

$2-3 \times 10^{23} \mathrm{~m}^{-2} \mathrm{~s}^{-1}$ at surface temperatures of 400,600 and $750{ }^{\circ} \mathrm{C}$ for 10 minutes (samples (i), (ii), (iii)). Until around $450^{\circ} \mathrm{C}$ no clear surface modification was observed. Above that temperature voids

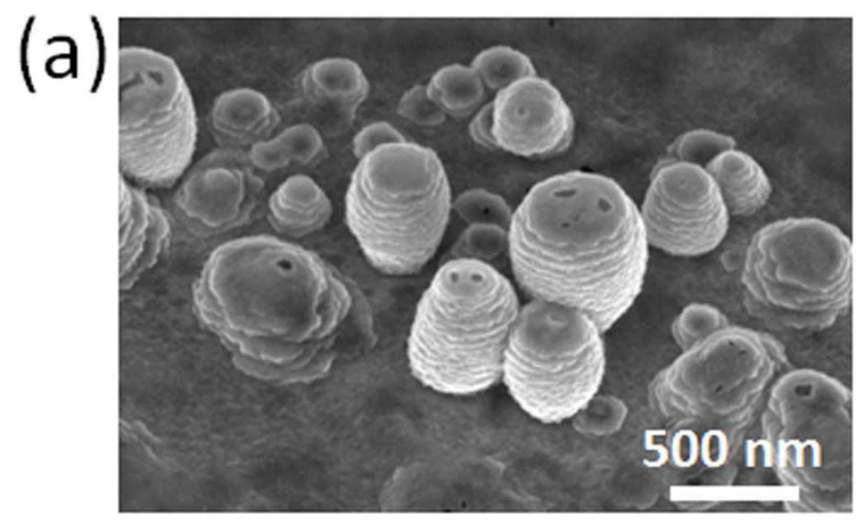

(b)

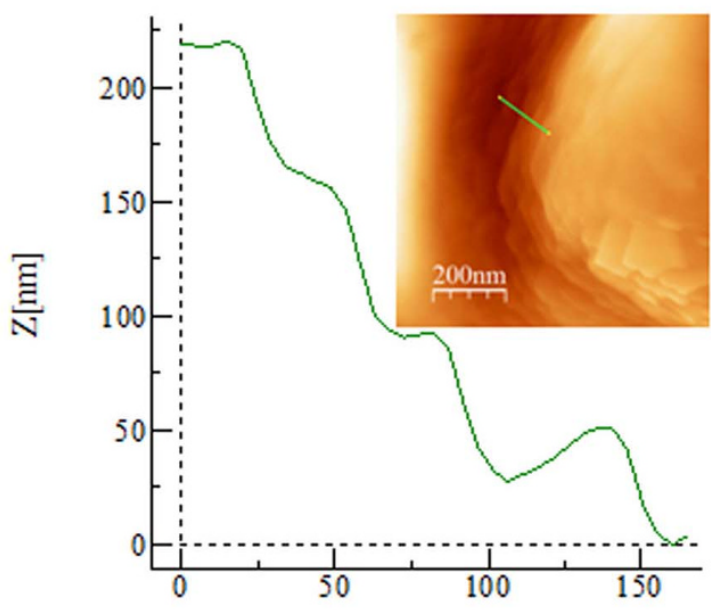

$\mathrm{X}[\mathrm{nm}]$

Figure $5 \mid$ (a) SEM image $\left(30^{\circ}\right.$ tilt) taken from sample (viii) (exposure conditions: $25 \mathrm{eV}, 250^{\circ} \mathrm{C}, 10$ minutes) and (b) AFM image of a structure existing on the same sample. start to appear on the surface. As seen in SEM images in (Figure 1.), the areal density of these voids increased with the surface temperature. SEM images were analyzed by the Gwyddion software to specify the mean void size. ${ }^{37}$ There is also a slight increase in the mean diameter of these voids, from $20 \mathrm{~nm}$ (88 voids were taken into analysis) to $25 \mathrm{~nm}$ (104 voids were taken into analysis) with an increase in surface temperature from $600^{\circ} \mathrm{C}$ to $750^{\circ} \mathrm{C}$. The sample exposed with surface temperature of $750^{\circ} \mathrm{C}$ was prepared by FIB milling method to get a cross section view. At the beginning of the FIB analysis, a region with an area of $2 \mu \mathrm{m} \times 6 \mu \mathrm{m}$ was coated by Pt to protect that region from the $\mathrm{Ga}$ ions. Hence, the etched side gives information about the cross section view of these structures. Voids, which are smaller than $100 \mathrm{~nm}$ in diameter, are detected with a wide size distribution underneath the surface (Figure 2.). When these surfaces are compared with other studies in literature, they show a resemblance to those observed after exposures of $\mathrm{W}$ and Mo to low energy $(\sim 20 \mathrm{eV}) \mathrm{He}$ ions. ${ }^{15}$ In that study, an increase of the ion energy to $45 \mathrm{eV}$ led to nanostructure growth. Although the ion energy is around $45 \mathrm{eV}$ in our study, no nanostructure growth is observed.

The surface temperature was increased above $850^{\circ} \mathrm{C}$ (sample (iv)(vii), Figure $3 \mathrm{a}-\mathrm{d}$ ). Beyond that temperature, the surface seems to be roughened and reformed. Nanosized structures start to be observed beyond $1000^{\circ} \mathrm{C}$ at an ion energy of $45 \mathrm{eV}$, whereas similar nanosized structures are observed at surface temperatures starting from $850^{\circ} \mathrm{C}$ if the ion energy is increased up to $70 \mathrm{eV}$. The number of the nanosized structures on a given area tends to decrease by a factor of around 2.5 and the mean diameter is shifted from $36 \mathrm{~nm}$ to $53 \mathrm{~nm}$ with increase in surface temperature from $850^{\circ} \mathrm{C}$ to $1000^{\circ} \mathrm{C}$ (Figure 3c,d.).

Aluminum. Aluminum surfaces were exposed to He plasma with an ion flux in the range of $3-4 \times 10^{23} \mathrm{~m}^{-2} \mathrm{~s}^{-1}$ and an ion energy of $25 \mathrm{eV}$ at a surface temperature of $250^{\circ} \mathrm{C}$. On these surfaces, randomly located structures besides some voids are detected. (Figure 4a,b) show that for longer exposures the spatial distribution of the structures becomes more homogenous and the average size of voids tends to increase with time.

Since the melting temperature of $\mathrm{Al}$ is relatively low (around $660^{\circ} \mathrm{C}$ ) compared to the other metals investigated here, the surface 


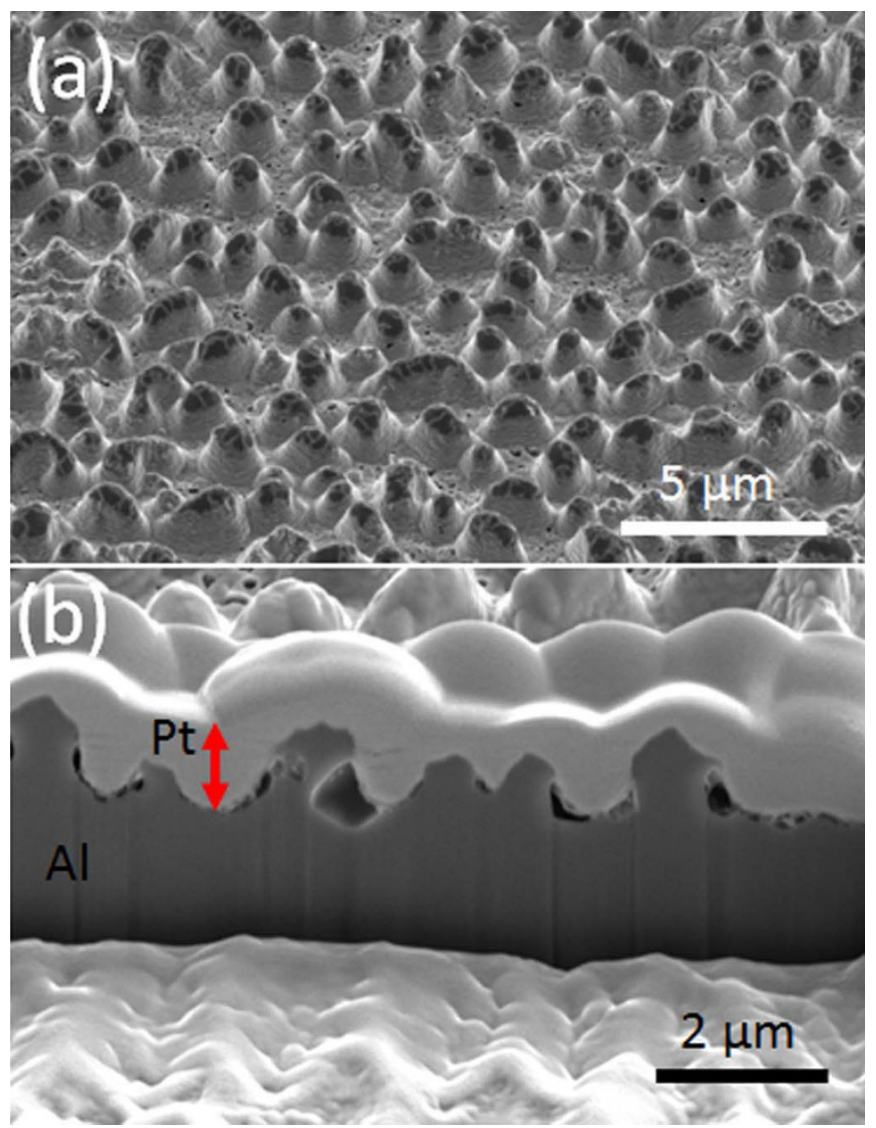

Figure 6 | (a) SEM image ( $52^{\circ}$ tilt) of $\mathrm{Al}$ surface which was irradiated by $\mathrm{He}$ ions with ion energy of $35 \mathrm{eV}$ with surface temperature of $250^{\circ} \mathrm{C}$

(sample (x)) and (b) a cross sectional image which was taken from the region seen in (a) (white layer seen on top is $\mathrm{Pt}$ which was coated during FIB milling).

temperature was kept constant at $250^{\circ} \mathrm{C}$. Besides the exposure time, the effect of ion energy on surface modification was studied. A significant change in both size and shape of structures is observed with a slight increase in average ion energy, of only $10 \mathrm{eV}$ (see Figure 4c,d). The mean diameter of the structures formed become around $1.4 \mu \mathrm{m}$ and the voids around $150 \mathrm{~nm}$.

The tilted SEM image (Figure $5 \mathrm{a}$ ) shows that surface is covered by individual structures with different heights. Although it is hard to judge from a top view image, the structures seem to be formed of several layers. To gain more insight, AFM measurement has been done on sample (viii). AFM measurement of one of these structures shows that these structures are formed by layers with thickness of around $50 \mathrm{~nm}$ (Figure 5b).

In order to clarify the surface modification mechanism, cross sectional images were taken from the sample prepared by FIB milling method. (Figure 6) exhibits the effect of He ions on surface modification with the presence of voids underneath the surface of the sample $(\mathrm{x})$.

Copper. Copper surfaces were irradiated by He ions with flux of $5-7 \times 10^{23} \mathrm{~m}^{-2} \mathrm{~s}^{-1}$ and at an ion energy of $25 \mathrm{eV}$. The surface temperature during these exposures was kept in the intermediate temperature range $\left(0.3 T_{m}<T<0.5 T_{m}\right)$ and exposures were repeated for two different durations, 10 and 30 minutes. As seen in (Figure 7), no significant change in the form of nanostructures can be observed for different exposure times. With the increase in surface temperature, individual structures tend to enlarge and then connect to each other for both exposure times.

Similarly to the Al surfaces, sample (xii) was prepared by FIB milling and a cross sectional image was taken. As seen in (Figure 8), a nanostructured layer with a thickness of around $100 \mathrm{~nm}$ is observed without any trace of He-induced voids.

Copper surfaces were exposed at higher temperatures, above $0.5 T_{m}$ resulting in significant changes in morphology. The structures observed at the highest temperature for our range resemble the ones on $\mathrm{Al}$, but in this case they are homogenously distributed and almost in the same size, around $240 \mathrm{~nm}$ in diameter (Figure 9). (Figure 10) shows the cross sectional views of samples (xv) and (xvi). In contrast with the samples exposed with lower surface temperature $\left(<400^{\circ} \mathrm{C}\right)$, voids are clearly detected underneath the surface. The homogenously distributed structures, which are formed after exposure at $650^{\circ} \mathrm{C}$, are clearly visible on the cross sectional images in (Figure 10b) and seem to have pillar-like shape.
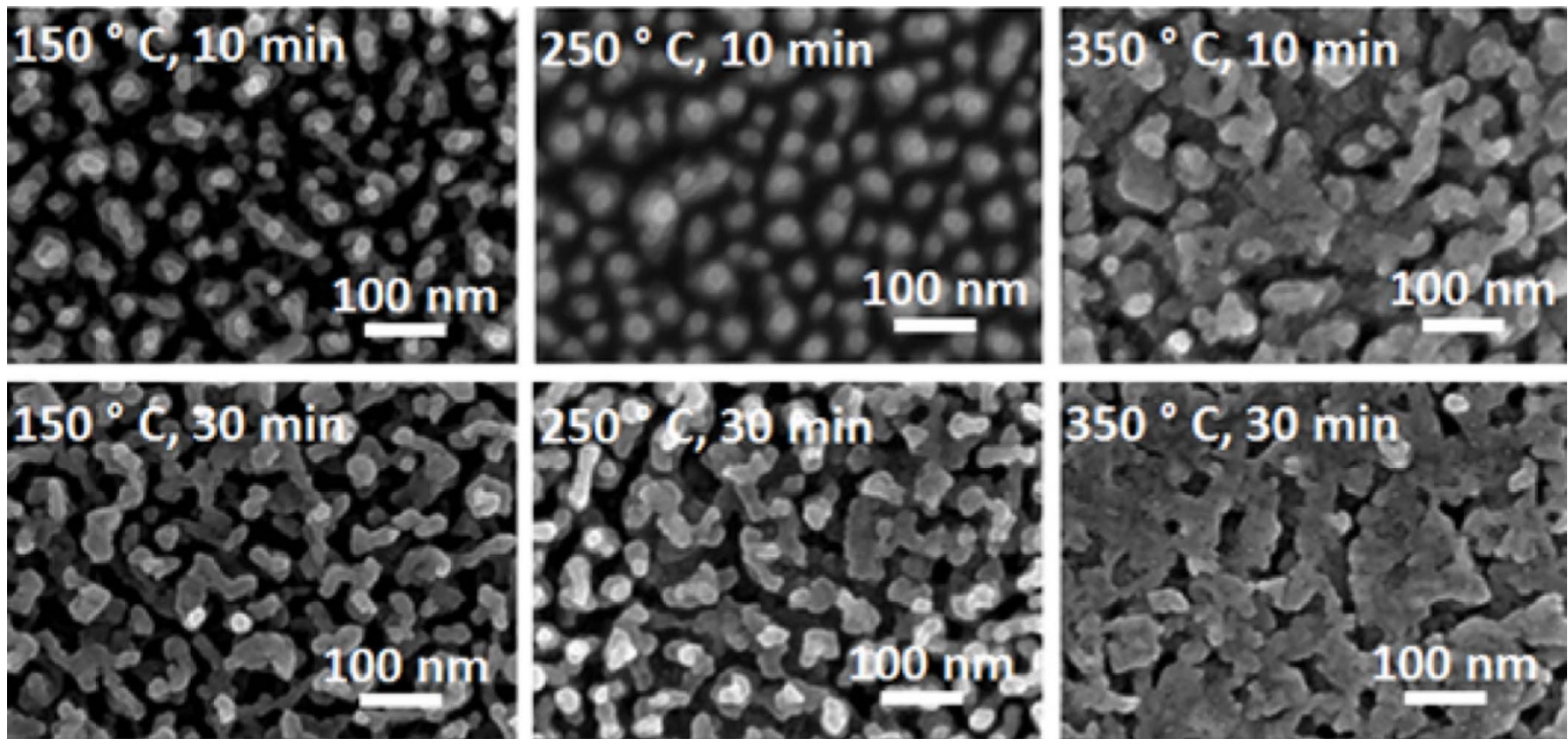

Figure $7 \mid$ Evolution of $\mathrm{Cu}$ nanostructures with surface temperature $\left(150-350^{\circ} \mathrm{C}, 0.31-0.46 \mathrm{~T}_{\mathrm{m}}\right)$ and exposure time (10, $\left.30 \mathrm{minutes}\right)$. 


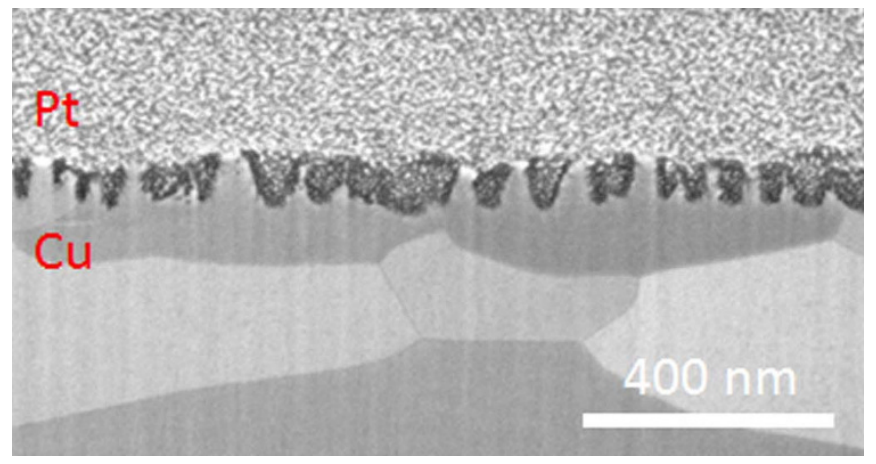

Figure 8 Cross sectional image of $\mathrm{Cu}$ surface, which was exposed to helium plasma with surface temperature of $250^{\circ} \mathrm{C}$ for 10 minutes (sample (xii)) prepared by FIB milling method.

\section{Discussion}

In order to observe the variation in efficacy of $\mathrm{He}$ ion induced surface modification of metals with different crystal structures, we investigated $\mathrm{Ti}$, which has hcp type crystal structure, and $\mathrm{Al}$ and $\mathrm{Cu}$, which have fcc type crystal structure, under similar irradiation conditions. Our results show that He ions could penetrate and form voids underneath the surface in all metals that we worked with. However, in terms of the resulting surface modifications different metals behave differently. Ti exposures do not show any nanostructure growth on the surface, which seems consistent with the expectations considering its densely packed crystal structure or low population of interstitials which mostly mediate effective He diffusion in the metal. Kajita et al. recently published an extensive study on the surface modification of titanium after He plasma exposure. ${ }^{38}$ Significant changes in surface morphology have been observed with slight differences in irradiation conditions, such as ion energy. Most of their exposures are conducted at higher ion energy $(>70 \mathrm{eV})$ than in our experiments. For that ion energy range, cone like structures are observed on the surface due to the enhanced effect of physical sputtering. For slightly lower ion energies $(\sim 50 \mathrm{eV}),{ }^{38}$ void formation has been reported on the surface, which is quite similar to what is observed in our experiments at similar surface temperatures and ion energy value $(\sim 45 \mathrm{eV})$. Besides that, the morphology obtained at $927^{\circ} \mathrm{C}$ (Figure 2 in Ref. 38.) is similar to the surfaces obtained at $850^{\circ} \mathrm{C}$ in our experiments. In that temperature range, the surface seems to be roughened and nanosized structures are formed.

Once the survey shifted to metals with lower mass compared to tungsten and molybdenum, other effects have to be invoked in the explanation of surface modifications under low energy $\mathrm{He}$ ion irradiations. Our previous work and also other studies suggested physical sputtering as an additional mechanism which contributes to the surface modification. ${ }^{16,17,39}$ In studies conducted on tungsten and molybdenum the sputtering yield is considered as negligible, since the ion energy in those studies is typically well below the threshold energy for physical sputtering. In our study, the mass loss is measured by weighing the samples before and after the plasma exposure. The sputtering yield is then determined by using the following expression:

$$
Y=\frac{\Delta m}{M_{2} n_{1}} N_{0}
$$

where $\Delta m$ is mass loss, $M_{2}$ - atomic mass of metal of interest, $n_{1}$ number of He ions reaching the surface and $N_{o}$ - Avogadro's number.

The sputtering yields measured here (taken on samples (i)-(xix)) are compared with the fit to several calculated values. ${ }^{40}$ (Figure 11) shows that our values are around one order of magnitude below the expected sputtering yields of the metals that we worked with. It is worth to note that the calculations are usually done by assuming a nearly flat surface, i.e. the effect of surface morphology on the sputtering yield is not taken into account. The curvature dependent sputtering has already been proposed in Sigmund's theory. ${ }^{41}$ Based on that theory, an analytical formula for the morphology dependent sputtering yield is developed and accordingly a decrease in sputtering yield is predicted with the development of surface morphology. ${ }^{42}$ The morphological change induced here by $\mathrm{He}$ ion irradiation is more complex than a symmetrical structure, hence one would expect to have enhanced deviation between calculated and experimental data. The variation in the sputtering yield of flat and modified surface has been reported after a similar experimental study as well. Nishijima
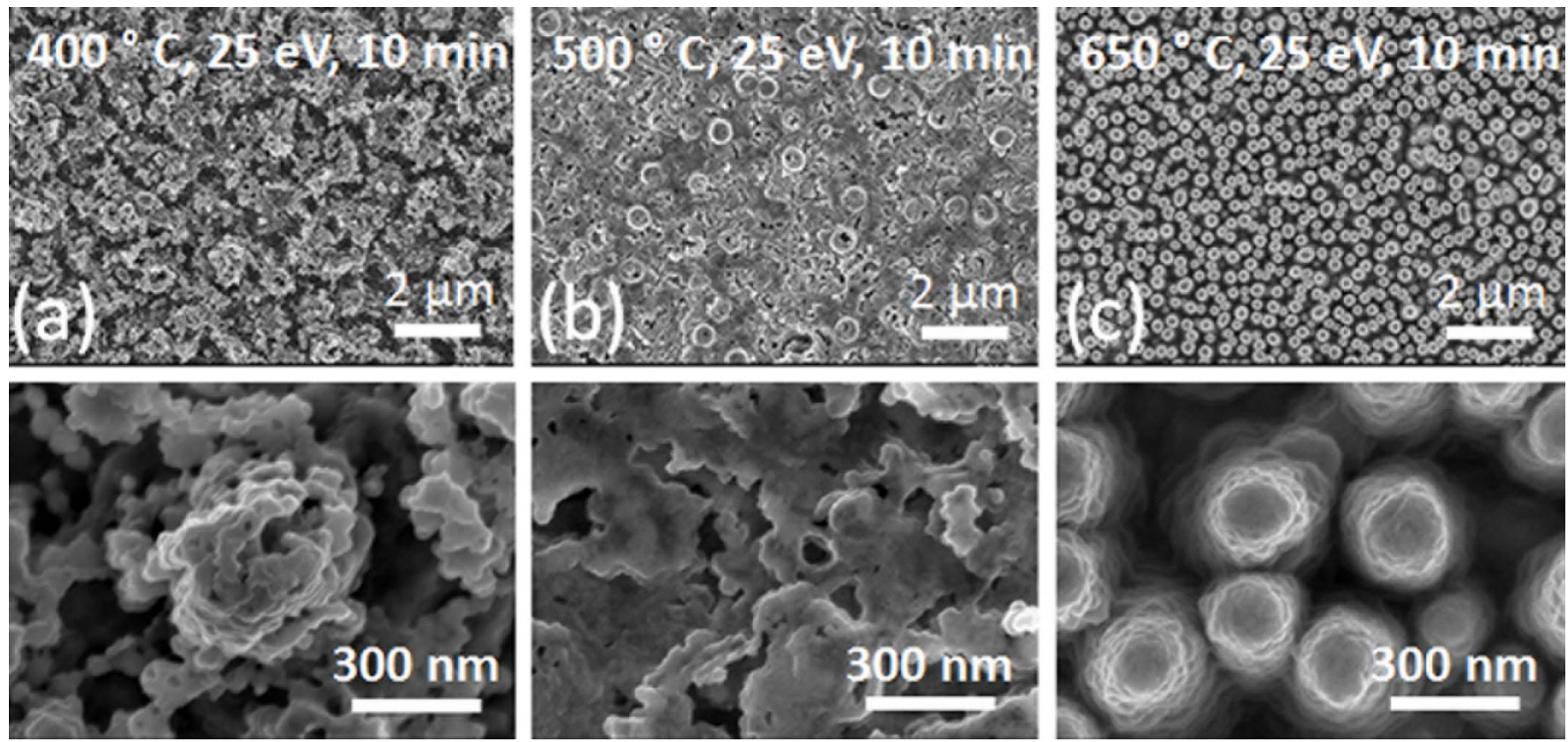

Figure 9 SEM images of surfaces which are irradiated by He ions with ion energy of $25 \mathrm{eV}$ at surface temperatures of (a) $400^{\circ} \mathrm{C}(0.50 \mathrm{~T} m)($ sample (xiv)), (b) $500^{\circ} \mathrm{C}\left(0.57 \mathrm{~T}_{\mathrm{m}}\right)$ (sample (xv)) and (c) $650^{\circ} \mathrm{C}\left(0.68 \mathrm{~T}_{\mathrm{m}}\right)$ sample (xvi). Images in the lower row are taken under higher magnification. 

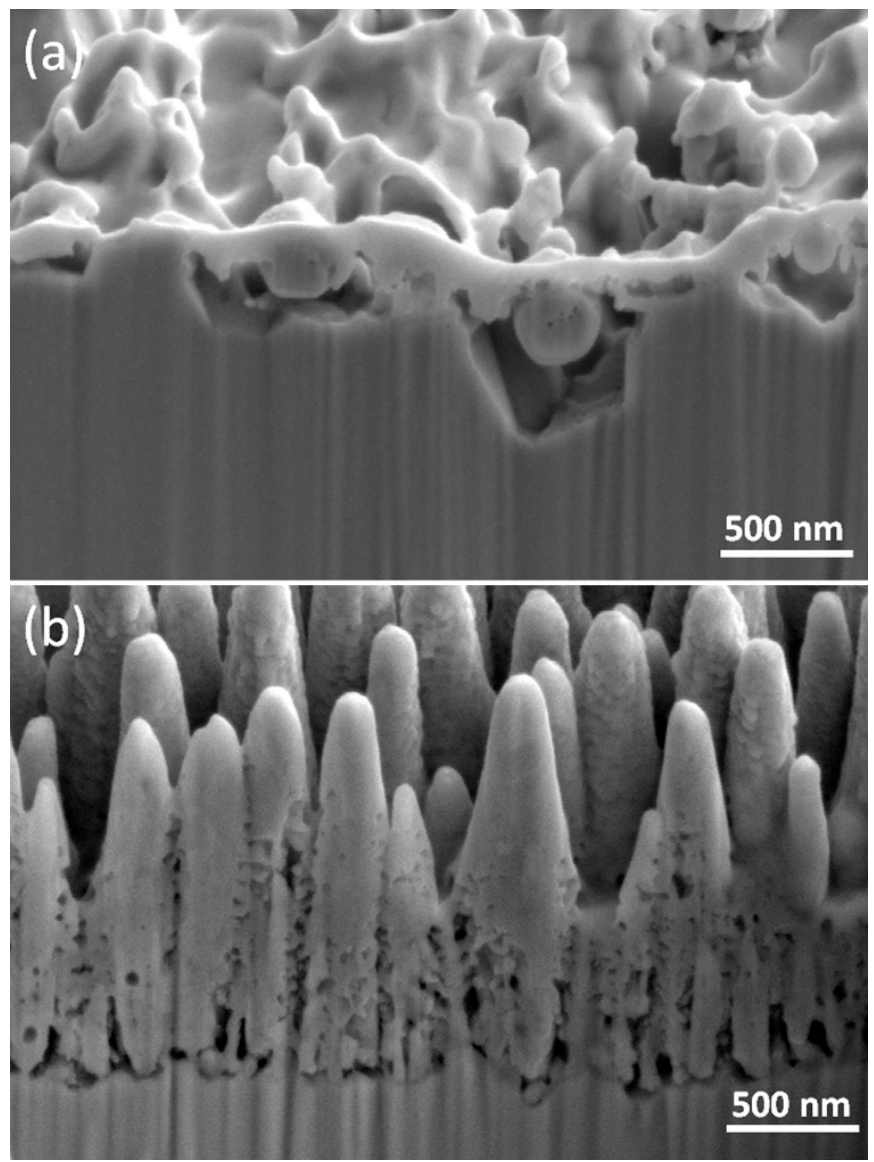

Figure 10 Cross section images of samples, which are exposed to helium plasma with surface temperatures of (a) $500^{\circ} \mathrm{C}$ (sample (xv)) and (b) $650^{\circ} \mathrm{C}$ (sample (xvi)).

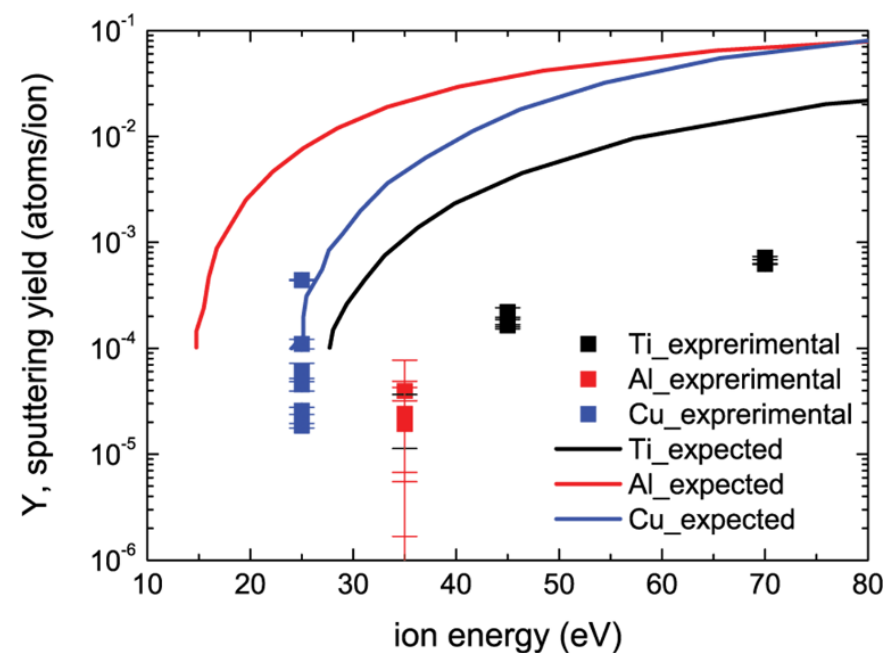

Figure $11 \mid$ Sputtering yield of $\mathrm{Ti}, \mathrm{Al}$ and $\mathrm{Cu}$ regarding to our mass loss measurements and literature values ${ }^{41}$.

et al. have shown that the sputtering yield of nanostructured tungsten derived from mass loss measurements are around one order of magnitude lower than the values calculated by TRIM code. ${ }^{43}$ The deviation in the calculated and experimental results is in agreement with our results. Different from the other metals, the sputtering yield for Al that we obtained from our experiments is around two orders of magnitude lower than the literature values. Since $\mathrm{Al}$ is quite reactive and native aluminum oxide (most likely, $\mathrm{Al}_{2} \mathrm{O}_{3}$ ) has higher binding
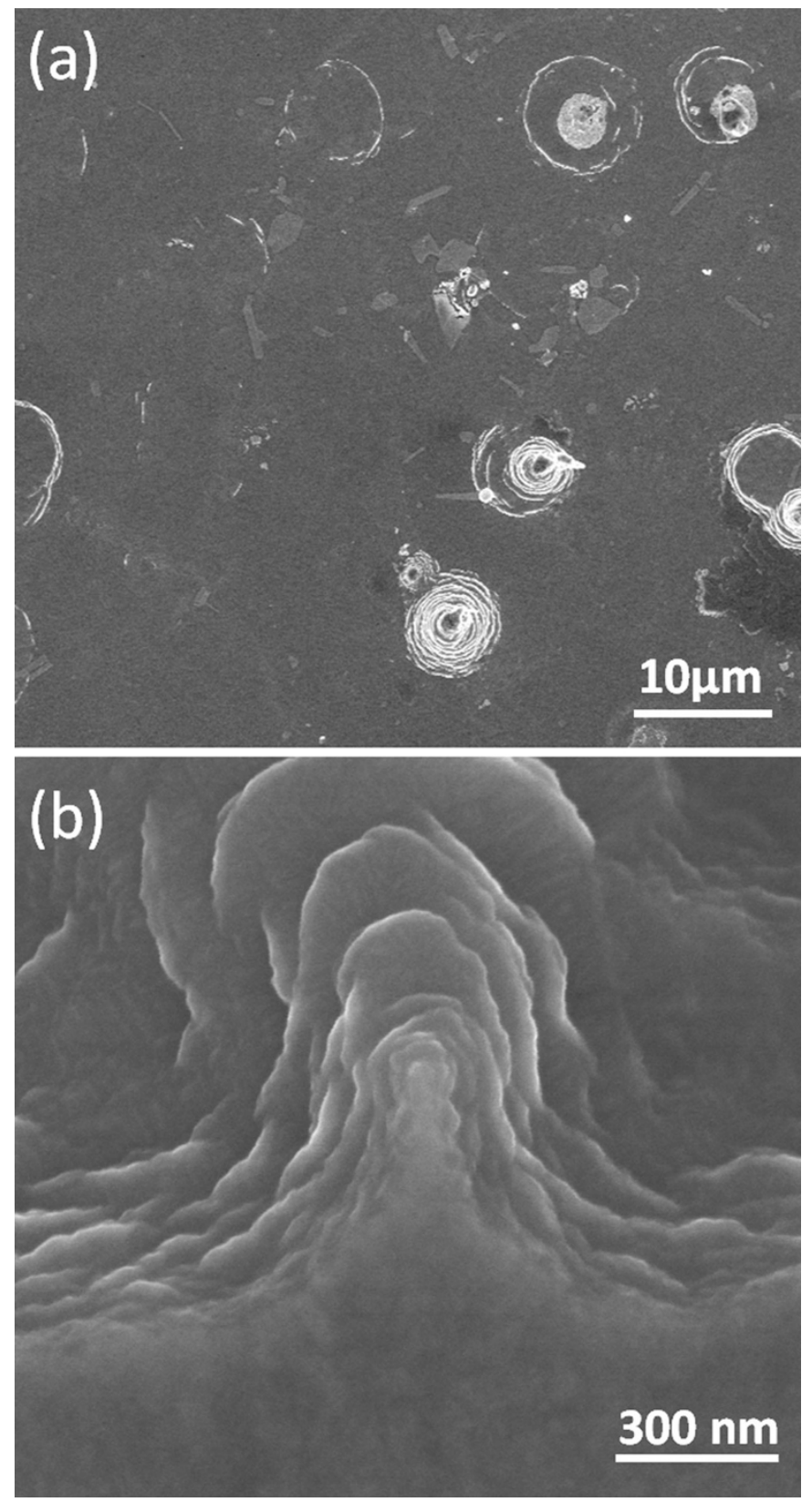

Figure $12 \mid$ SEM images of Al surface after Ar plasma exposure taken under low (a) and high (b) magnification.

energy than $\mathrm{Al}$, we would expect a decrease in sputtering yield for samples (viii)-(x).

The structures on $\mathrm{Al}$ and $\mathrm{Cu}$ surfaces show similarity with the selforganized nanopatterns and nanodots obtained by ion beam sputtering. ${ }^{44,45}$ The formation of these patterns is explained as a result of interplay between ion sputtering, which induces surface roughening, and surface diffusion, which induces smoothing. ${ }^{44}$ To investigate the role of physical sputtering on the observed morphology changes, several studies have been conducted on $\mathrm{W}$ and Ti surfaces exposed to both Ar and Ne plasma for W, and Ne plasma for Ti. In neither of those cases, nanostructure formation or bubble growth beneath the surface were detected. ${ }^{38,46}$ Similarly, Al surfaces were exposed to Ar ions and (Figure 12) shows that Ar ions induce no surface modification except for some sparse structures whose layered structure resembles the nanostructures formed under He plasma. However, there is no significant similarity between surfaces after He and Ar plasma exposures, namely neither homogenously located nanostructures nor voids 
are detected. Hence, the surface modifications that we observe on $\mathrm{Al}$ and $\mathrm{Cu}$ cannot be only attributed to physical sputtering caused by any ion species. The effect of He clustering and consequently void formation on surface modification is clearly seen on $\mathrm{Al}$ and $\mathrm{Cu}$ surfaces. Both $\mathrm{He}$ ion irradiation and physical sputtering would be considered as effective factors in the morphology changes of $\mathrm{Cu}$ and $\mathrm{Al}$.

Titanium, aluminum and copper surfaces were exposed to pure He plasmas to study the associated morphology changes. Different surface modifications were observed among these metals. The experimental studies show that it is rather hard to rely on a single material property in order to predict the behavior of metals after helium plasma exposures. The effect of physical sputtering on surface modification is clearly seen for $\mathrm{Al}$ and $\mathrm{Cu}$ surfaces. Homogenously distributed nano pillars are observed on these metals. Any significant surface modification could not be observed for $\mathrm{Ti}$, which might be resulted because of its closely packed structure and low sputtering yield. Once the nano pillars formed on $\mathrm{Cu}$ surfaces are oxidized, they could be of interest for further energy applications, such as electrochemical reductions of $\mathrm{CO}_{2}$ and photoelectrochemical water splitting, because of their homogenous distribution and high aspect ratios. ${ }^{47}$

1. Frost, F., Ziberi, B., Schinler, A. \& Rauschenbach, B. Surface engineering with ion beams: from self-organized nanostructures to ultra-smooth surfaces. Appl. Phys. A 91, 551-559 (2008).

2. Ziberi, B., Frost, F., Tartz, M., Neumann, H. \& Rauschenbach, B. Importance of ion beam parameters on self-organized pattern formation on semiconductor surfaces by ion beam erosion. Thin Solid Films 459, 106-110 (2004).

3. Yewande, E. O., Hartmann, A. K. \& Kree, R. Propagation of ripples in Monte Carlo models of sputter-induced surface morphology. Phys. Rev. B: Condensed Matter 71, 195405-8 (2005)

4. Iwakiri, H., Yasunaga, K., Morishita, K. \& Yoshida, N. Microstructure evolution in tungsten during low-energy helium ion irradiation. J. Nucl. Mater. 283-287, 1134-1138 (2000).

5. Ullmaier, $H$. The influence of helium on the bulk properties of fusion reactor structural materials. Nucl. Fusion 24, 1039-1083 (1984).

6. Trinkaus, H. Energetics and formation kinetics of helium bubbles in metals, Radiation Effects. Radiation Effects 78, 189-211 (1983).

7. Kornelsen, E. V. \& Van Gorkum, A. A. A study of bubble nucleation in tungsten using thermal desorption spectrometry: Clusters of 2 to 100 helium atoms. J. Nucl. Mater. 92, 79-88 (1980).

8. Kajita, S., Sakaguchi, W., Ohno, N., Yoshida, N. \& Saeki, T. Formation process of tungsten nanostructure by the exposure to helium plasma under fusion relevant plasma conditions. Nucl. Fusion 49, 095005-6 (2009).

9. Nishijima, D., Ye, M. Y., Ohno, N. \& Takamura, S. Incident ion energy dependence of bubble formation on tungsten surface with low energy and high flux helium plasma irradiation. J. Nucl. Mater. 313-316, 97-101 (2003)

10. Baldwin, M. J., Doerner, R. P., Nishijima, D., Tokunaga, K. \& Ueda, Y. The effect of high fluence mixed-species (deuterium, helium, beryllium) plasma interactions with tungsten. J. Nucl. Mater. 390-391, 886-890 (2009).

11. Iyyakkunnel, S. et al. Morphological Changes of Tungsten Surfaces by Low-Flux Helium Plasma Treatment and Helium Incorporation via Magnetron Sputtering. ACS Appl. Mater. Interfaces 6, 11609-11616 (2014).

12. Takamura, S., Ohno, N., Nishijima, D. \& Kajita, S. Formation of nanostructured tungsten with arborescent shape due to helium plasma irradiation. Plasma Fusion Res. 1, 051 (2006).

13. Baldwin, M. \& Doerner, R. Helium induced nanoscopic morphologhy on tungsten under fusion relevant plasma conditions. Nucl. Fusion 48, 035001-5 (2008).

14. Kajita, S., Saeki, T., Yoshida, N., Ohno, N. \& Iwamae, A. Nanostructured Black Metal: Novel Fabrication Method by Use of Self-Growing Helium Bubbles. Appl. Phys. Express 3, 085204 (2010).

15. De Temmerman, G. et al. Nanostructuring of molybdenum and tungsten surfaces by low-energy helium ions. J. Vac. Sci. Technol. A. 30, 041306-6 (2012).

16. Kajita, S. et al. Helium plasma implantation on metals: Nanostructure formation and visible-light photocatalytic response. J. Appl. Phys. 113, 134301-7 (2013).

17. Tanyeli, I., Marot, L., van de Sanden, M. C. M., \& De Temmerman, G. Nanostructuring of Iron Surfaces by Low-Energy Helium Ions. ACS Appl. Mater. Interfaces 6, 3462-3468 (2014).

18. Sivula, K., Le Formal, F. \& Grätzel, M. Solar Water Splitting: Progress Using Hematite $\left(\alpha-\mathrm{Fe}_{2} \mathrm{O}_{3}\right)$ Photoelectrodes. ChemSusChem. 4, 432-449 (2011).

19. Berger, S., Tsuchiya, H., Ghicov, A. \& Schmuki, P. High photocurrent conversion efficiency in self-organized porous $\mathrm{WO}_{3}$. Appl. Phys. Lett. 88, 203119 (2006).

20. Brillet, J., Grätzel, M. \& Sivula, K. Decoupling feature size and functionality in solution-processed, porous hematite electrodes for solar water splitting. Nano Lett. 10, 4155-4160 (2010).
21. de Respinis, M. et al. Efficient Plasma Route to Nanostructure Materials: Case Study on the Use of $\mathrm{m}-\mathrm{WO}_{3}$ for Solar Water Splitting. ACS Appl. Mater. Interfaces 5, 7621-7625 (2013).

22. Henriksson, K. O. E., Nordlund, K. \& Keinonen, Molecular dynamics simulations of helium cluster formation in tungsten. J. Nucl. Instr. Meth. Phys. Res. B 244, 377-391 (2006).

23. Stewart, D., Osetskiy, Y. \& Stoller, R. Atomistic studies of formation and diffusion of helium clusters and bubbles in BCC iron. J. Nucl. Mater. 417, 1110-1114 (2011).

24. Trinkaus, H. \& Singh, B. N. Helium accumulation in metals during irradiation where do we stand? J. Nucl. Mater. 323, 229-242 (2003).

25. Fahlman, B. D. Materials Chemistry [2 ${ }^{\text {nd }}$ edition] (Springer, Dordrecht, Heidelberg, London, New York, 2011).

26. Wilson, W. D. \& Johnson, R. A. [Rare Gases in Metals], Interatomic Potentials and Simulation of Lattice Defects [Gehlen, P. C., Beeler, J. R. \& Jaffee, R. I. (eds.)] (Plenum Press, New York, 1972).

27. van Veen, A. \& Caspers, L. M. Proc. Consultants Symp. on Inert gases in metals (Harwell, U.K., 1979).

28. Wang, Y., Liu, S., Rong, L. \& Wang, Y. Atomistic properties of helium in hcp titanium: A first-principles study. J. Nucl. Mater. 402, 55-59 (2010).

29. Ao, B. Y., Yang, J. Y., Wang, X. L., \& Hu, W. Y. Atomistic behavior of helium-vacancy clusters in aluminum. J. Nucl. Mater. 350, 83-88 (2006).

30. Baskes, M. I., \& Melius, C. F. Pair potentials for fcc metals. Phys. Rev. B 20, 3197-3204 (1979).

31. Jing, P., Khraishi, T., Young, J. A. \& Wirth, B. D. Multi-scale simulations of the effects of irradiation-induced voids and helium bubbles on the mechanical properties of aluminum. Philos. Mag. 85, 757-767 (2005).

32. Yang, L., Zu, X. T. \& Gao, F. Ab initio study of formation, migration and binding properties of helium-vacancy clusters in aluminum. Physica B: Condensed Matter 403, 2719-2724 (2008).

33. Baldwin, M. J. \& Doerner, R. P. Formation of helium induced nanostructure 'fuzz' on various tungsten grades. J. Nucl. Mater. 404, 165-173 (2010).

34. Evans, J. H. Breakaway bubble growth during the annealing of helium bubbles in metals. J. Nucl. Mater. 334, 40-46 (2004).

35. De Temmerman, G., Zielinski, J. J., van Diepen, S., Marot, L. \& Price, M. ELM simulation experiments on Pilot-PSI using simultaneous high flux plasma and transient heat/particle source. J. Nucl. Mater. 51, 073008-8 (2011).

36. Bystrov, K., van der Vegt, L., De Temmerman, G., Arnas, C. \& Marot, L. Reorganization of graphite surfaces into carbon micro- and nanoparticles under high flux hydrogen plasma bombardment. J. Vac. Sci. Technol. A 31, 011303 (2013).

37. Klapetek, P. \& Necas, D. Gwyddion, Czech Metrology Institut, Brno, Czech Republic, (2007).

38. Kajita, S. et al. Surface modification of titanium using He plasma. Appl. Surf. Sci. 303, 438-445 (2014).

39. Doerner, R. P., Baldwin, M. J. \& Stangeby, P. C. An equilibrium model for tungsten fuzz in an eroding plasma environment. Nucl. Fusion 51, 043001-6 (2011).

40. Carter, G., Navinsek, B. \& Whitton, J. L. Sputtering by Ion Bombardment II [Behrisch, R. (ed.)] (Springer, Berlin, 1983).

41. Sigmund, P. Theory of Sputtering. I. Sputtering Yield of Amorphous and Polycrystalline Targets. Phys. Rev. 184, 383-416 (1969).

42. Wei, Q., Eddy, M., Li, K. D. \& Wang, L. Influence of surface morphology on sputtering yields. J. Phys. D:Appl. Phys. 42, 165304-6 (2009).

43. Nishijima, D., Baldwin, M. J., Doerner, R. P. \& Yu, J. H. Sputtering properties of tungsten 'fuzzy' surfaces. J. Nucl. Mater. 415, S96-S99 (2011).

44. Facsko, S. et al. Formation of Ordered Nanoscale Semiconductor Dots by Ion Sputtering. Science 285, 1551-1553 (1999).

45. Munoz-Garcia, J. et al. [Self-Organized Surface Nanopatterning by Ion Beam Sputtering] Toward Functional Nanomaterials, Lecture Notes in Nanoscale Science and Technology 5 [Wang, Z. M. (ed.)] (Springer Science+Business Media, LLC 2009).

46. Yajima, M. et al. Comparison of Damages on Tungsten Surface Exposed to Noble Gas Plasmas. Plasma Sci. Technol. 15, 282 (2013).

47. Sen, S., Liu, D. \& Palmore, G. T. R. Electrochemical Reduction of $\mathrm{CO}_{2}$ at Copper Nanofoams. ACS Catal. 4, 3091-3095 (2014).

\section{Acknowledgments}

This work is part of the research program of the Stichting voor Fundamental Onderzoek der Materie (FOM), which is financially supported by the Nederlandse Organisatie voor Wetenschappelijk Onderzoek (NWO). It is supported by the European Communities under the contract of Association between EUROTAM and FOM and was conducted within the framework of the European Fusion Programme.

\section{Author contributions}

The experiments were planned by I.T. and G.d.T. and conducted by I.T. SEM measurements and FIB milling were performed by D.M. The results were discussed by I.T., M.C.M.v.d.S. and G.d.T. Manuscript was written by I.T. with improvements from G.d.T., M.C.M.v.d.S. and L.M. 


\section{Additional information}

Competing financial interests The authors declare no competing financial interests.

How to cite this article: Tanyeli, İ., Marot, L., Mathys, D., van de Sanden, M.C.M. \&

De Temmerman, G. Surface Modifications Induced by High Fluxes of Low Energy Helium

Ions. Sci. Rep. 5, 9779; DOI:10.1038/srep09779 (2015).

This work is licensed under a Creative Commons Attribution 4.0 International License. The images or other third party material in this article are included in the article's Creative Commons license, unless indicated otherwise in the credit line; if the material is not included under the Creative Commons license, users will need to obtain permission from the license holder in order to reproduce the material. To view a copy of this license, visit http://creativecommons.org/licenses/by/4.0/ 